\title{
1 Forest cover and social relations are more important than economic 2 factors in driving hunting and bushmeat consumption in post-frontier 3Amazonia
}

\section{Abstract}

5Identifying the economic drivers of hunting and bushmeat consumption is crucial for 6understanding whether economic growth in tropical forest regions can foster poverty 7alleviation and biodiversity conservation. However, studies investigating those drivers 8have drawn contrasting conclusions. Some authors attribute inconsistent findings to 9heterogeneous spatial and environmental contexts, yet other studies indicate that social 10 factors may predominate over economical determinants. Here, we investigate bushmeat 1 lhunting and consumption by analyzing the relative importance of household-scale 12economic factors in diverse spatial and environmental contexts. We surveyed 240 13 households distributed across twenty diverse rural landscapes in a post-frontier region in 14Brazilian Amazonia. Our results show that hunting is more likely in locations with 15higher forest cover, where game availability is expected to be higher. In contrast, 16 bushmeat consumption is widespread even in deforested landscapes near to urban 17centers. However, we find no evidence that household-scale economic factors determine 18variation in rural bushmeat consumption, regardless of spatial or environmental context. 19Consequently, we infer that future growth in income or wealth would be unlikely to 20significantly change patterns of bushmeat hunting and consumption. Instead, we find 21 that eating bushmeat is mainly dependent on the hunting of relatively common species 22 for subsistence and food sharing, rather than through market exchange. This 23demonstrates an important informal economy maintained by social relations. Work is 24 needed to evaluate the sustainability of hunting these relatively small to medium-sized 25 species given they evidently provide useful ecosystem service to poor households and 26are likely to support social relations in rural Amazonia.

27Keywords: Income, game availability, harvest, sharing, wildlife conservation, 28wildmeat.

\section{9}

\section{Introduction}

31 Understanding the drivers of bushmeat consumption is a long-standing concern in 32 conservation science, as bushmeat use is recognized for both its importance to human 33populations and its threat to biodiversity (Milner-Gulland 2003; Nielsen et al. 2018). 34Identifying the economic drivers is particularly important because this knowledge 35 provides insights into how economic changes (e.g. market expansion, market 36integration, projects and policies aimed at increasing household income) can affect 37 bushmeat use. Researchers have been particularly interested in determining whether 38poverty alleviation and wealth creation strategies are likely to decrease bushmeat 39hunting and consumption. This so-called win-win scenario for development and 40biodiversity conservation would not occur if, instead, economic growth leads to 41 increased bushmeat demand and more hunting (Milner-Gulland et al. 2003; Brashares et 42al. 2011). Resolving the economic basis of wildlife use is important in rural areas of the 43 forested tropics because of high but changing rates of multi-dimensional poverty 44(Sunderlin et al. 2008). 
46 consumption offers divergent predictions about what happens with wealth grow (being

47asset-wealth or monetary income) (Milner-Gulland et al. 2003), depending on

48preferences for bushmeat relative to other forms of animal protein. Where bushmeat is 49relatively cheap and accessible and people would rather replace it with other available 50 meat types (i.e. bushmeat is an inferior good), bushmeat consumption would decline 51 with wealth rise (Wilkie \& Godoy 2001). Alternatively, if considered largely equivalent 52 to other forms of animal protein (i.e. a normal good), then increased wealth should 53 translate into a proportional increase in bushmeat consumption. Finally, if bushmeat is a 54 preferred source of animal protein (i.e. a superior good) then we would expect rising 55 wealth to lead to a disproportionately high increase in consumption (Wilkie \& Godoy 562001; Wilkie et al. 2005; Fa et al. 2009; Godoy et al. 2010).

57 Because we do not know whether bushmeat is an inferior, normal or superior 58good, it is unclear whether wealth creation is likely to decrease or increase pressure on 59 wildlife. In fact, empirical assessments of the economic drivers of bushmeat 60 consumption have provided contrasting conclusions about the direction of the 61relationship between wealth and consumption (e.g. Wilkie \& Godoy 2001; Fa et al. 622009; Godoy et al. 2010).

63 Evidence from Africa and Amazonia suggests these divergences may reflect 64spatial and environmental contexts (e.g. proximity to urban centers and local forest 65 cover), which affect bushmeat demand and supply. Remoteness from urban centers can 66 decrease the availability of domestic sources of protein, resulting in high prices and high 67bushmeat demand (Chaves et al. 2017a). Bushmeat may therefore be a necessity (i.e. an 68inferior good) in remote places, which is substituted by other meats when they become 69 available or wealth increases. Such localities are also less deforested, according to a von 70Thunian model of higher transport costs and lower land rents with distance from cities 71(Angelsen 1994). Hence, the abundance of many game species should be higher, 72increasing their supply. This situation would offer greater net benefits of hunting and 73 bushmeat consumption, especially for poorer households with less access to traded 74domesticated meats. Indeed, when harvestable wildlife populations are more easily 75available (e.g. near to protected areas, large forest patches), bushmeat prices tend to be 76 lower and its consumption rate higher (Brashares et al. 2011; Foerster et al. 2012; 77Torres et al. 2018). In contrast, nearer to urban centers, domestic sources of protein are 78cheaper and bushmeat can be relatively expensive due to distance and transport costs 79 from high-forest cover hunting areas. There, Brashares et al. (2011) found that wealthier 80 households consume more bushmeat than poorer ones, indicating bushmeat as a normal 81or superior good. Summarizing, increasing wealth appears to impact game populations 82differently, depending on the spatial and environmental context.

83 It is problematic that only one study has formally addressed how economic 84 drivers of bushmeat consumption interact with spatial and environmental factors. To our 85knowledge, Brashares et al.'s (2011) African study provides the only insights. Indeed, 86 most bushmeat research is based on work in West and Central Africa, where there is 87intense, large-scale trade in bushmeat markets (Dupain et al. 2012; Petrozzi et al. 2016). 88Market exchange may be less important for determining bushmeat consumption in other 89places. In Latin America, studies evaluating this relationship have focused on urban 90areas (Parry et al. 2014; Morsello et al. 2015; Chaves et al. 2019) or in semi-autarkic 91 indigenous groups (Wilkie \& Godoy 2001; Godoy et al. 2010; Vasco \& Sirén 2016). 92Moreover, analysis of consumption has tended not to distinguish whether bushmeat was 
93hunted by household members or acquired through exchange, purchase, or sharing. 94Clearly, prices of bushmeat and domestic meat are likely to affect bushmeat 95consumption more through trade than through subsistence hunting.

96 In this paper, we investigate bushmeat hunting and consumption from the novel 97perspective of analyzing the relative importance of household-level economic factors in 98diverse spatial and environmental contexts. We did so by surveying households across 99twenty rural landscapes with varied urban-remoteness and local forest cover. We 100addressed five interrelated questions: Are economic factors associated with (i) hunting 101 and (ii) bushmeat consumption? If so, is the relationship between economic factors and 102(iii) hunting, or (iv) bushmeat consumption, dependent on spatial and environmental 103factors? (v) Does the relationship between economic factors and bushmeat consumption 104differ between households that hunted and those that acquired bushmeat by alternative 105ways (i.e. purchase or gift)?

\section{Methods}

\subsection{Study region}

1080ur study was carried out at a meso-scale in eastern Brazilian Amazonia, in rural areas 109of three municipalities: Santarém (78 790 rural inhabitants from 294580 in total); 110Belterra (6 852 of 16318 ); and Mojuí dos Campos, a recently established municipality 111 with no data on rural population (combined rural and urban population of 15232 ) 112(IBGE 2010). The two smaller towns are c.30-45 km by paved road from Santarém. 113Bordered by the Amazon, Tapajós and Curuá-Una Rivers, our study region 114encompasses approximately 1 million ha (Fig. 1) of a diverse mosaic evolved over 115 decades of government policies and economic cycles. Although above half of the region 116 is still covered by primary/secondary forests (Fig. 1), there is a gradient in forest cover 117 (correlated with distance to urban areas), and a diversity of socioeconomic contexts (e.g. 118rural population density, property sizes, wealth and market access) (details in Appendix 119A.1).

120 In Brazil, commercial hunting is illegal in any circumstances, although it still 121 occurs and may involve large volumes in urban settings of remote Amazonian towns 122(van Vliet et al. 2015; El-Bizri et al. 2020; Chaves et al. 2019). Subsistence hunting has 123an uncertain legal status. The Brazilian Wildlife Protection Act (1967) made hunting 124wildlife illegal, although subsequent laws allowed hunting by traditional and rural 125populations only in a "state of necessity" or "to quench hunger" (Antunes et al. 2019).

\subsection{Sampling design}

$127 \mathrm{We}$ used a hierarchical sampling design. We first selected twenty 7850 -ha areas 128 (circular with a $5 \mathrm{~km}$ radius), hereafter landscapes, that captured variability in forest 129 cover (33\% to 93\%) and road distance from Santarém $(10-140 \mathrm{~km})$. Within each 130landscape, we randomly selected 12 households $(n=240)$ (Fig. 1) by randomly drawing 13112 points along the paved, unpaved roads or rivers, using ArcGIS 9.3, ensuring $\geq 400 \mathrm{~m}$ 132 between them to avoid spatial clustering. The selected household was the nearest from 133the point drawn. We skipped households when household heads declined to participate $134(n=3)$, or if after three visits no resident was encountered $(n=4)$ (Appendix A.2).

\subsection{Data collection}


136To collect data on hunting and bushmeat consumption, as well as demographic and 137 socioeconomic characteristics of households, we conducted an interview-based survey 138with household heads (when possible, both heads) between July and November 2013. 139Beforehand, we pilot-tested the interview protocol for clarity, resolving any 140inconsistencies, and establishing a reliable recall period based on respondents' answers. 141The survey was conducted by P.C.T and three trained assistants (two from the region).

\subsubsection{Hunting and bushmeat consumption variables}

143We considered hunting and bushmeat consumption as count variables. Values were 144defined as the number of times anyone in the household had gone hunting in the 145previous 30 days - hereafter hunting frequency - and the number of times bushmeat was 146 consumed in the household in the previous 15 days - hereafter bushmeat consumption 147 frequency. Bushmeat consumption data was restricted to the previous 15 days based on 148the pilot study (Appendix A.3.1). For each hunting trip and meal containing bushmeat, 149we asked which species were hunted or consumed.

\subsubsection{Economic variables}

151 We estimated two economic variables - per capita monetary income (previous 30 days) 152and per capita asset-wealth. We used both indicators because they reflect different 153aspects of the household's economic condition. Monetary income measures transitory 154income, which may sharply fluctuate especially in rural areas, whereas asset-wealth 155reflects long-term economic conditions (Wilkie et al. 2005). Economic variables were 156measured in Brazilian Reais (1 Real =0.45 US\$, in December 2013) (Appendix A.3.2).

157 We winsorized the values of monetary income at the $97^{\text {th }}$ percentile to limit 158extreme values and reduce their possible spurious effect (Van Kerm 2007). Households 159above this percentile were either the few much richer households in the sample (both in 160terms of monetary income and wealth) or those that had an atypical high monetary 161income the previous month (earning from 2.5 to 25 times more income than those below 162the $97^{\text {th }}$ percentile). For the same purpose we winsorized the highest wealth value to the 163second highest value, as their difference was twofold (Fig. A.1). Monetary income and 164 wealth were weakly correlated (Pearson $=0.26, \mathrm{p}<0.001$ ).

\subsubsection{Spatial and environmental variables}

166We considered one spatial and one environmental variable: the time (in minutes) that 167household members took to reach the largest city, Santarém (collected through 168interviews) - hereafter 'remoteness' -, and the amount of forest cover surrounding the 169household - hereafter 'forest cover'. We considered time rather than distance because 170the former was less correlated with forest cover (Pearson $=0.64, \mathrm{p}<0.001$, against 171 Pearson $=0.88, \mathrm{p}<0.001$ for distance $[\mathrm{km}])$ and more appropriate for understanding urban 172accessibility and decision-making (Kwan 2013). We calculated forest cover (a proxy of 173game availability) as total forest cover $\left(\mathrm{km}^{2}\right)$, including primary forest (non-degraded 174 and degraded) plus mature secondary forest $(>10$ years) within a $10-\mathrm{km}$ radius $(31,400-$ 175ha) from the household (Appendix A.3.3).

\subsubsection{Control variables}

$177 \mathrm{We}$ used two additional variables as controls in our analyses, proxies of culture and 178education attainment, because they had been linked to hunting and bushmeat 179consumption (Poulsen et al. 2009; Foerster et al. 2012; Mgawe et al. 2012). For culture, 
180we used the origin of the household male head as a binary variable indicating whether 181he was born in the Legal Amazon (see Appendix A.3.4). Education attainment was 182 accessed by the number of schooling years of the male household head. We used data of 183the male head because only men reported hunting. For hunting, we used data of the 184woman head only when there was no male head. For bushmeat consumption, we 185 explored using also the maximum number of schooling years between the male and $186 \mathrm{female}$ heads and whether at least one of the heads was born in Legal Amazon, but the 187results did not change.

\subsection{Data analysis}

189We first tested and found no multicollinearity among independent variables (low values 190 of variance inflation factor; highest $\mathrm{VIF}=1.77$ ). There was considerable variation in 191economic and control variables within all landscapes (Table A.1).

192 To investigate the association between hunting and bushmeat consumption and 193the economic, spatial and environmental variables, we ran different sets of generalized 194linear mixed-effects models (GLMM) for each of the two dependent variables. We used $195 \mathrm{GLMM}$ to account for the hierarchical nature of the sampling design, with landscapes as 196random factors (Zuur et al. 2009). Alternative models in each set were compared using 197 the difference in their AICc values in relation to the first-ranked model $(\triangle \mathrm{AICc})$ 198(Burnham \& Anderson 2002). We considered that a value of $\triangle \mathrm{AICc} \leq 2$ indicates 199equally plausible models.

200 To answer questions (i) to (iv) we modeled both hunting and bushmeat 201consumption frequencies using zero-inflated Poisson models, because approximately 202 two thirds of the data for both dependent variables were zeros. These models treat the 203zero-count outcomes as a mixture of structural and sampling zeros, which allows us to 204 analyze both the variables associated with performing the behavior (hunted/did not hunt 205and consumed/did not consume bushmeat) and their frequencies (from zero on).

206 Both sets of candidate models (i.e. one set for hunting, another for bushmeat 207consumption) contained: an intercept-only model for reference (that did not include any 208fixed factors), a control model with only the two control variables as fixed effects, and 209additive and interaction models. Additive and interaction models always contained the 210 two control variables and combinations of economic, spatial and environmental 211 variables as fixed effects. We included only two-way interaction terms between 212economic variables and spatial or environmental variables (Table A.2).

213 To answer question (v) we considered only those households that consumed 214 bushmeat. Therefore, we modeled bushmeat consumption frequency using zero215truncated Poisson models. We used the Conway-Maxwell Poisson model to account for 216the underdispersed nature of our data, and included a binary variable - whether the 217 bushmeat consumed in the household was hunted by a household member or not. We 218added two-way and three-way interactions with this binary variable to each model to 219investigate whether any association between bushmeat consumption and the variables 220 and interactions previously tested differed between hunters and non-hunters' households 221(Table A.3).

222 We standardized all non-categorical fixed factors so that each had a mean of $223 z e r o$ and a standard deviation of one to improve convergence of the fitting algorithm 224(Zuur et al. 2009). We also tested the effect of the three continuous independent 
225variables as quadratic terms, to account for possible U-shaped associations with hunting 226 and bushmeat consumption (Wilkie \& Godoy 2001), but model fit was not improved. 227All analyses were implemented in $R$ 3.5.1 (R Core Team 2014) and all model selections 228were run using the glmmTMB package (Brooks et al. 2017). Selected models were 229tested for misspecification problems (e.g. uniformity, under or over dispersion and zero230inflation) using DHARMa package for residual diagnostics (Hartig 2019), and no such 231problems were found.

\subsection{Ethics statement}

233Our study protocol was evaluated and approved by a Research Ethics Committee from 234the Brazilian National Commission for Research Ethics (CAAE 16766413.4.0000.5464 235Plataforma Brasil). Prior to interviews, we contacted representatives of nearby rural 236communities, explaining the research. We later obtained their written voluntary and 237 informed consent. Then, we obtained written and informed consent from each 238participant before beginning the interview. At the interview onset, we explained the 239research aims, guaranteed the information anonymity and assured their participation 240was voluntary and they could withdraw at any time.

\section{Results}

$242 \mathrm{Members}$ of $31 \%$ of the surveyed households had hunted during the previous 30 days. 243In total, respondents declared 189 hunting events (mean $=0.8, \mathrm{SD}=1.5$ across all 244households; mean=2.6, $\mathrm{SD}=1.6$ across households that hunted), of which $47 \%$ were 245 successful ( $\geq 1$ animal caught), and 106 individuals caught. In $26 \%$ of households that 246 hunted, animals were never caught, while in $84 \%$ of successful hunting events, only one 247individual was caught (mean $=1.2$ animals, $\mathrm{SD}=0.5$ ).

248 Bushmeat consumption, not necessarily from their own hunting, was relatively 249 more common; $45 \%$ of the households had consumed it within the previous 30 days and $25033 \%$ within the previous 15 days. Respondents declared 208 meals containing bushmeat 251 in the previous 15 days (mean $=0.9$ meals, $S D=1.9$ across all households; mean $=2.6$, $252 \mathrm{SD}=2.5$ across households where bushmeat was consumed). The mean number of meals 253in households with a hunter was higher than in those that acquired bushmeat by other 254 means (mean=3.2, $\mathrm{SD}=2.9$ and mean $=1.8, \mathrm{SD}=1.4$, respectively). Perhaps surprisingly, 255 our data indicate very low levels of bushmeat trade in our rural study area. For 59\% of 256 the meals, bushmeat was hunted by a household member, in $40 \%$ bushmeat was a gift 257 from relatives, friends or neighbors, and for only two meals (1\%) bushmeat was 258purchased.

259 Paca (Cuniculus paca) and nine-banded armadillo (Dasypus novemcinctus) were 260the most frequently hunted and consumed species, accounting for nearly $80 \%$ of 261successful hunting trips and meals (Fig. 2).

\subsection{Hunting correlates}

263Hunting frequency was not associated with any factor investigated (Table 1). However, 264having hunted was strongly and positively associated with forest cover in the 265surroundings and with origin of the household head. Higher forest cover and 266Amazonian origin of the household head were associated with increased probability of 267 hunting, with hunting occurring in $37.7 \%$ of Amazonian origin households but only in $26820.2 \%$ of those non-Amazonian (Table 1, Fig. 3). People in households with non- 
269Amazonian origin were three times less likely to hunt than those with Amazonian origin 270 (odds-ratio $=0.32, \mathrm{CI}=0.16-0.65$, for the first selected model). Education had a U-shaped 271relationship with hunting probability, increasing through elementary education and 272decreasing with high-school education and beyond (Fig. 3). We found no association of 273 having hunted with household monetary income and wealth in any spatial or 274environmental context.

\subsection{Bushmeat consumption correlates}

276When considering all households sampled $(\mathrm{n}=240)$, bushmeat consumption within the 277 past 15 days (both binary and frequency variables) was not strongly associated with any 278 of the tested factors. We found weak evidence that people in households where the male 279had was non-Amazonian are two times less-likely to consume bushmeat than those 280where the male head had Amazonian origin (odds-ratio $=0.45, \mathrm{CI}=0.21-0.97$, for the 281 first selected model), although the upper confidence interval approaches 1, meaning the 282 two groups might have similar probabilities (Table B.1). However, we did not find this 283 effect when we considered the origin of both household heads that is, whether at least 284one of them was Amazonian.

285 Considering only households that consumed bushmeat within the past 15 days 286 $(n=80)$, we also found no evidence that consumption frequency is associated with any of 287 the tested factors and neither that it is associated with different factors for hunting 288households compared to non-hunting households. However, consumption frequency in 289hunting households was 2.7 times higher $(\mathrm{CI}=1.5-4.8)$ compared to non-hunting 290households, when controlling for other variables (Table B.2).

\section{Discussion}

292Hunting and bushmeat consumption in our study region were mainly driven by game 293availability and social relations and not market exchange. Wealth did not play an 294important role in in shaping neither hunting not bushmeat consumption, irrespective of 295the environmental and spatial context. This evidence contrasts with what has been 296suggested elsewhere (Fa et al. 2009; Brashares et al. 2011). As such, differences in 297 spatial and environmental contexts between regions investigated in previous studies 298may not explain all the contrasting findings of those studies about the association of 299 economic factors and bushmeat consumption. Overall, our findings suggest that the way 300 bushmeat is acquired is crucial in defining the drivers of hunting and bushmeat 301consumption.

302 Conventionally, access to bushmeat is conceptualized as playing out through 303market exchange involving rational economic actors, with markets then responding 304 predictably to spatiotemporal variation in supply and demand (e.g. Wilkie \& Godoy 3052001). Yet, buying bushmeat was rare in our rural study area. Instead, households 306tended to acquire it directly through hunting, or through an 'economy of affection' 307 within social networks. We found no evidence that economic factors are key in 308determining hunting or bushmeat consumption, irrespective of spatial and 309 environmental factors. As such, variations in income or wealth levels would unlikely 310lead to major changes in hunting and bushmeat consumption in our study region and 311similar post-frontier Amazonian regions.

312 Moreover, by investigating hunting, we tested whether the economic 313determinants of consumption are conditional on how bushmeat is acquired. We found 
314no evidence of this between hunting and sharing, which were the prevalent ways in our 315 study area. Hunting was more likely in locations with higher forest cover, where game 316availability is likely higher. Instead, bushmeat consumption was widespread.

\subsection{Hunting in a post-frontier region}

318We found that hunting is more likely in less-deforested landscapes, confirmatory of 319other studies identifying that hunting is more likely when living closer to game sources 320(i.e. large forest patches or protected areas) or areas with high forest cover (as proxies of 321 game availability) (Shively 1997; Brashares et al. 2011; Torres et al. 2018). We also 322 found that hunting was more prevalent among 'Amazonian' (as opposed to in-migrants 323from elsewhere in Brazil) headed households. This may result from culturally-based 324differences (Mgawe et al. 2012) or hunting expertise passed across generations. Yet, 325 hunting frequency was not associated with any factor investigated, which may result 326 from limited variation in our sample, as most households $(60 \%)$ reported hunting just 327 once or twice in the last 30 days. Those species most frequently hunted were smaller 328 and classified as least concern (IUCN Red List), which seems consistent with more 329deforested and overhunted tropical forests, where hunters catch commonly occurring 330species instead of preferred ones (e.g. Southeast Asia - Rao et al. 2010). Nonetheless, 331 even in highly forested regions of the Amazon, C. paca is widely hunted and a preferred 332species (Parry et al. 2014; Valsecchi et al. 2014; Nunes et al. 2019). Low occurrence of 333large-bodied species (i.e. deer, peccaries, tapir) catches is likely to indicate their 334depressed populations in our post-frontier study region. Local depletion and extinction. 335 of large-bodied species has already been suggested by another study in the region 336(Sampaio et al. 2010).

\subsection{Rural bushmeat consumption outside of market exchange}

338 Our results differ from previous work, in diverse contexts, which found that monetary 339income or asset-wealth were important in explaining bushmeat consumption (e.g. 340Wilkie \& Godoy 2001; Wilkie et al. 2005; Fa et al. 2009; Godoy et al. 2010; Brashares 341et al. 2011; Foerster et al. 2012). Notably, almost none of the surveyed households in 342 our study reported they had purchased bushmeat. Instead, most rural consumers had 343obtained bushmeat directly from the surrounding forest or farm-fallow matrix or 344received as a gift. Because bushmeat trade is illegal in Brazil and only one household 345reported purchasing bushmeat, we might have underestimated trade. Nonetheless, the 346lack of association between consumption and micro-economic factors suggests trade is 347relatively unimportant in the rural zone of our study region. Although we report almost 348 no trade within rural areas, we cannot discard that rural hunters may be selling meat 349directly in the urban area or to traders and therefore, supplying local urban markets with 350these relatively common 'post-depletion' mammal species. Rural-urban bushmeat 351networks are found elsewhere in Amazonia, although even urban consumers often 352obtain bushmeat through gifting instead of trade (Morsello et al. 2015; van Vliet et al. 3532015, Chaves et al. 2019).

354 Elsewhere, the lack of correlation between bushmeat consumption and wealth 355 has been explained by high prevalence of consumption together with harvest being 356consumed mostly within hunting households (Schulte-Herbrüggen et al. 2013). 357Likewise, here, in all but three hunting events, at least part of the catch was consumed 358in the hunter's household. In $43 \%$ of all successful catches, bushmeat was also shared, 359 and in $13 \%$ of those cases it was shared with relatives or friends that lived far away $360(>50-\mathrm{km})$. That might explain why bushmeat consumption was so widespread in the 
361region, even in more deforested landscapes and in less-remote places with greater 362 access to other meat types. Sharing often involves reciprocity and is considered very 363important in rural areas_(e.g. Nunes et al. 2019). Consequently, bushmeat gifting 364belongs to the informal economy and is still critical to people whose economic lives sit 365somewhere between subsistence peasantry and market economy. This informal 366economy has been termed 'economy of affection' to describe kin-based networks of 367exchange in East Africa (Hyden 1983). In rural Amazonia, continued reliance on this 368informal system of production and exchange helps maintain bonds between households, 369 enhances social cohesion and contributes to survival, with bushmeat being a very 370 frequent gift (WinkerPrins \& Souza 2005; Minzenberg \& Wallace 2011; Nunes et al. 3712019).

372 Although we did not find an association between economic factors and overall 373 consumption, this linkage might exist for particular species, as found in rural Africa and 374Asia (Foerster et al. 2012; Shively 1997) and urban Amazonia (Parry et al. 2014). In our 375 study region, there were mainly two species consumed (C. paca and D. novemcinctus) $376(80 \%$ of bushmeat meals, combined), the only ones we had enough consumption events 377 to rigorously test such association. Again, we failed to find any association of economic 378 factors and the consumption of these animals in any spatial and environmental context 379(Table S6).

380 Geographical origins, used as a proxy for culture, was not a strong driver of 381 bushmeat consumption. This finding echoes Morsello et al.'s (2015) findings from 382Amazonian towns. Interestingly, their urban study also found social relations were 383stronger predictors of bushmeat consumption than economic factors. Those who 384believed that sharing bushmeat strengthens social bonds (with family and friends) were 385 more likely to consume and to prefer it over other animal proteins. Gifts were the 386 second most important source of bushmeat in our sample and hunters often shared their 387 catch, which both suggest that social relations play important roles in our study region, 388consistent with work elsewhere in Amazonia, and in Africa (Morsello et al. 2015; van 389Vliet et al. 2015; Bachmann et al. 2019; Chaves et al. 2019; Nunes et al. 2019).

\subsection{Implications for conservation and rural livelihoods}

391As relatively self-sufficient rural populations experience changing economic conditions 392through market integration, government-led development projects and cash transfer 393programs, it becomes increasingly important to understand how these changes affect 394livelihood strategies, resource use and biodiversity conservation (Billé et al. 2012). Our 395results suggest neither hunting nor bushmeat consumption in our study region is likely 396 to be affected by changes in levels of households' monetary income or wealth. Hence, 397 public policies aimed at increasing monetary income in rural households are unlikely to 398impact hunted wildlife.

399 Hunting seems instead driven by environmental factors associated with wildlife 400 availability and cultural preferences or experience. Bushmeat consumption, on the other 401hand, seems strongly linked to social relations, through an 'economy of affection' based 402on small to medium-bodied size common species. Nevertheless, the scale of the any 403 urban trade supplied by rural hunters is unclear. The apparent scarcity of the larger404bodied or sensitive Amazonian game species suggests these are probably severely 405depleted or even locally extinct in our study region. In fact, other studies in the region, 406 using interviews and line-transects, have found higher abundance of small-bodied 407 species such as nine-banded armadillo (Dasypus novemcinctus) and agouti (Dasyprocta. 
408 leporina) and very low abundance or evidence of local extinction of medium and large409bodied species, such as tapir (Tapirus terrestris) and white-lipped peccary (Tayassu. 410pecari) (Sampaio et al. 2010; Ravetta 2015). Collared peccary (Pecari tajacu) and 411 brocket deer (Mazama spp.) may persist in fragmented landscapes, although red brocket 412 deer (Mazama americana) had lower abundance in such landscapes than in locations 413with continuous forest. The same was observed for agouti (Sampaio et al. 2010). This 414 may explain the higher hunting frequency of agouti we found in more forested 415 landscapes and some of those adjacent to a protect area (Tapajós National Forest) (Fig. 4162).

417 Although bushmeat is probably consumed not only for necessity, bushmeat 418 consumption is widespread, suggesting the remnant hunted mammal species provide 419 critical sources of macro- and micro-nutrients for more deprived households, 420particularly in rural areas far from rivers. In addition, bushmeat gifting contribute to 421support social bonds (Minzenberg \& Wallace 2011) that may provide both hunting and 422non-hunting households with nutrients in times of need, favoring food security (Nunes 423et al. 2019).

424 Regarding wildlife conservation, there is evidence from other Amazonian 425 regions that species associated with agricultural areas (crop-raiding species) (e.g. 426 lowland paca, agouti, collared peccary, brocket deer) are more frequently hunted (Nunes 427 et al. 2020) and frequently detected in early successional forests (Abrahams et al. 2018). 428 Hunters in larger villages use smaller catchment areas and harvest more game per unit 429time than hunters in smaller villages, suggesting that forests around agricultural areas 430can sustain hunting of crop-raiding species (Nunes et al. 2020). However, evaluating431 monitoring the sustainability of hunting even common species is key, as there is also 432 evidence that even populations of such species (e.g. C. paca) may be susceptible to 433overhunting (Valsecchi et al. 2014). In our study region, red brocket deer has been 434 found to be absent from some locations where forest is fragment (Sampaio et al. 2010). 435Therefore, interventions that reduce hunting and consumption of species that are already 436 depleted in some locations is important. Research shows that awareness of overhunting 437(Morsello et al. 2015; Bachmann et al. 2019; Kouassi et al. 2019), and community 438engagement activities (Steinmetz et al. 2014; Chaves et al. 2017b) can reduce trade and 439 consumption in rural and urban areas. However, these mechanisms may not work 440everywhere (e.g. Chausson et al. 2019, in an urban African context). Interventions 441aimed at decreasing overall levels of hunting by rural populations may constrain access 442to an important ecosystem service, disturb social relations and lack popular support. 443Therefore, campaigns to avoid hunting locally-scarce species could be more successful 444if rural Amazonians in post-frontier regions are allowed to hunt more resilient species 445sustainably.

\section{Acknowledgements}

447We are grateful to: P.C.R de Araújo and E.R. da Silva for assistance in data collection; 448K.S. Gonçalves for assistance in mapping roads and households and pilot-testing 449interviews; J.V. Siqueira for mapping forest cover; and all interviewees and community 450representatives in Santarém, Mojuí dos Campos and Belterra.

\section{Funding sources}

452This work was supported by the Fundação de Amparo à Pesquisa do Estado de São 453Paulo-FAPESP [grant numbers 2011/19108-0, 2011/19606-0]; the Conselho Nacional 
454de Desenvolvimento Científico e Tecnológico - CNPq [grant numbers 306715/2011-2, 455308205/2014-6, 311051/2018-9]; the Coordenação de Aperfeiçoamento de Pessoal de 456Nível Superior - CAPES.

\section{Appendix A and B. Supplementary material}

458Supplementary data to this article can be found online.

\section{References}

460Abrahams MI, Peres CA. Costa HCM. 2018. Cassava loss by terrestrial vertebrates in 461 western Brazilian Amazonia. Journal of Wildlife Management 82: 734-746.

462Angelsen A. 1994. Shifting Cultivation Expansion and Intensity of Production: The 463 Open Economy Case. Chr. Michelsen Institute for Development Studies and Human 464 Rights. Working Paper 1994:3. Bergen. Available from

465 http://bora.cmi.no/dspace/bitstream/10202/355/1/WP1994.3\%20Arild-

466 07192007_7.pdf

467Antunes AP, et al. 2019. A conspiracy of silence: Subsistence hunting rights in the 468 Brazilian Amazon. Land Use Policy 84: 1-11.

469Bachmann ME, Junker J, Mundry R, Nielsen MR, Haase D, Cohen H, Kouassi JAK, 470 Kühl HS. 2019. Disentangling economic, cultural, and nutritional motives to identify 471 entry points for regulating a wildlife commodity chain. Biological Conservation 238 472 DOI: 10.1016/j.biocon.2019.07.022.

473Billé R, Lapeyre R, Pirard R. 2012. Biodiversity conservation and poverty alleviation: a 474 way out of the deadlock? SAPIENS 5: 1-15.

475Brashares J S, Golden CD, Weinbaum KZ, Barret CB, Okello GV. 2011. Economic and 476 geographic drivers of wildlife consumption in rural Africa. Proceedings of the

477 National Academy of Sciences of the United States of America 108: 13931-13936.

478Brooks ME, Kristensen K, van Benthem KJ, Magnusson A, Berg CW, Nielsen A, 479 Skaug HJ, Maechler M, Bolker BM. 2017. glmmTMB Balances Speed and

480 Flexibility Among Packages for Zero-inflated Generalized Linear Mixed Modeling.

481 The R Journal 9: 378-400.

482 https://journal.r-project.org/archive/2017/RJ-2017-066/index. html.

483Burnhan KP, Anderson D. 2002. Model selection and multi-model inference: A practical 484 information-theoretic approach. $2^{\text {nd }}$ edition. Springer-Verlag, New York.

485Chausson AM, Rowcliffe JM, Escouflaire L, Wieland M, Wright JH. 2019.

486 Understanding the Sociocultural Drivers of Urban Bushmeat Consumption for

487 Behavior Change Interventions in Pointe Noire, Republic of Congo. Human Ecology 488 47: 179-191.

489Chaves WA, Wilkie DS, Monroe MC, Sieving KE. 2017a. Market access and wild meat 490 consumption in the central Amazon, Brazil. Biological Conservation 212: 240-248. 
491Chaves WA, Valle DR, Monroe MC, Wilkie DS, Sieving KE. 2017b. Changing wild 492 meat consumption: an experiment in the central Amazon, Brazil. Conservation

493 Letters 11: 1-10.

494Chaves WA, Monroe MC, Sieving KE. 2019. Wild meat trade and consumption in the 495 central Amazon, Brazil. Human Ecology 47: 733 - 746.

496Dupain J, Nackoney J, Vargas JM, Johnson PJ, Farfán MA, Bofaso M, Fa JE. 2012.

497 Bushmeat characteristics vary with catchment conditions in a Congo market.

498 Biological Conservation 146: 32-40.

499El-Bizri HR, et al. 2020. Urban wild meat consumption and trade in central Amazonia. 500 Conservation Biology 34: 438-448.

501Fa JE, Albrechtsen L, Johnson PJ, Macdonald DW. 2009. Linkages between household 502 wealth, bushmeat and other animal protein consumption are not invariant: evidence 503 from Rio Muni, Equatorial Guinea. Animal Conservation 12: 599-610.

504Foerster S, Wilkie DS, Morelli GA, Demmer J, Starkey M, Telfer P, Steil M, Lewbel 505 A. 2012. Correlates of bushmeat hunting among remote rural households in Gabon, 506 Central Africa. Conservation Biology 26: 335-344.

507Godoy R, et al. 2010. The effect of wealth and real income on wildlife consumption 508 among native Amazonians in Bolivia: estimates of annual trends with longitudinal 509 household data (2002-2006). Animal Conservation 13: 265-274.

510Hartig F. 2019. DHARMa: Residual Diagnostics for Hierarchical (Multi-Level / Mixed)

511 Regression Models. R package version 0.2.4.

512 https://CRAN.R-project.org/package=DHARMa.

513Hyden G. 1983. No Shortcuts to Progress: African Development Management in 514 Perspective. Heinemann, London.

515Instituto Brasileiro de Geografia e Estatística (IBGE) 2010. Censo Demográfico 2010. 516 IBGE, Rio de Janeiro, Rio de Janeiro.

517Kouassi JAK, Normand E, Koné I, Boesch C. 2019. Bushmeat consumption and 518 environmental awareness in rural households: a case study around Taï National Park, 519 Côte d'Ivoire. Oryx 53: 293-299.

520Kwan M-P. 2013. Beyond space (as we knew it): Toward temporally integrated 521 geographies of segregation, health, and accessibility. Annals of the Association of 522 American Geographers 103: 1078-86.

523Mgawe P, Mulder MB, Caro T, Martin A, Kiffner C. 2012. Factors affecting bushmeat 524 consumption in the Katavi-Rukwa ecosystem of Tanzania. Tropical Conservation 525 Science 5: 446-462.

526Milner-Gulland E.J, Bennet EL, SCB 2002 Annual Meeting Wild Meat Group. 2003. 527 Wild meat: the bigger picture. Trends in Ecology and Evolution 18: 351-357.

528Minzenberg E, Wallace R. 2011. Amazonian agriculturalists bound by subsistence 529 hunting. Journal of Cultural Geography 28: 99-121. 
530Morsello C, Yague B, Beltreschi L, van Vliet N, Adams C, Schor T, Quiceno-Mesa MP, 531 Cruz D. 2015. Cultural attitudes are stronger predictors of bushmeat consumption 532 and preference than economic factors among urban Amazonians from Brazil and 533 Colombia. Ecology and Society 20: 21. DOI: 10.5751/ES-07771-200421.

534Nielsen MR, Meilby H, Smith-Hall C, Pouliot M, Treue T. 2018. The importance of 535 wild meat in the Global South. Ecological Economics 146: 696-705.

536Nunes VA, Guariento RD, Santos BA, Fischer E. 2019. Wild meat sharing among non537 indigenous people in the southwestern Amazon. Behavioral Ecology and 538 Sociobiology 73: 26 DOI: 10.1007/s00265-018-2628-x.

539 Nunes AV, Oliveira-Santos LGR, Santos BA, Peres CA, Fischer E. 2020.

540 Socioeconomic drivers of hunting efficiency and use of space by traditional

541 Amazonians. Human Ecology DOI: 10.1007/s10745-020-00152-6.

542Parry L, Barlow J, Pereira H. 2014. Wildlife Harvest and Consumption in Amazonia's 543 Urbanized Wilderness. Conservation Letters 7: 565-574.

544Petrozzi F, Amori G, Franco D, Gaubert P, Pacini N, Eniang EA, Akani GC, Politano E, 545 Luiselli L. 2016. Ecology of bushmeat trade in west and central Africa. Tropical 546 Ecology 57: 545-557.

547Poulsen JR, Clark CJ, Mavah G, Elkan PW. 2009. Bushmeat supply and consumption in 548 a tropical logging concession in northern Congo. Conservation Biology 23: 15975491608.

550R Core Team 2015. R: The R Project for Statistical Computing. Available at

551 https://www.r-project.org/.

552Rao M, Htun S, Zaw T, Myint T. 2010. Hunting, Livelihoods and Declining Wildlife in 553 the Hponkanrazi Wildlife Sanctuary, North Myanmar. Environmental Management 554 46: 143-153.

555Ravetta AL. 2015. Distribuição e abundância de médios e grandes mamíferos na 556 Amazônia Central. PhD Thesis. Universidade Federal do Pará, Belém, Brazil.

557 Sampaio R, Lima AP, Magnusson WE, Peres CA. 2010. Long-term persistence of 558 midsized to large-bodied mammals in Amazonian landscapes under varying contexts 559 of forest cover. Biodiversity and Conservation 19: 2421-2439.

560Shively GE. 1997. Poverty, technology, and wildlife hunting in Palawan. Environmental 561 Conservation 24: 57-63.

562Schulte-Herbrüggen B, Cowlishaw G, Homewood K, Rowcliffe JM. 2013. The 563 importance of bushmeat in the livelihoods of West African cash-crop farmers living 564 in a faunally-depleted landscape. PLoS ONE 8 DOI: 10.1371/journal.pone.0072807.

565Steinmetz R, Srirattanaporn S, Mor-Tip J, Seuaturien N. 2014. Can community outreach 566 alleviate poaching pressure and recover wildlife in South-East Asian protected areas? 567 Journal of Applied Ecology 51: 1469-1478.

568Sunderlin WD, Dewi S, Puntodewo A, Müller D, Angelsen A, Epprecht M. 569 2008. Why forests are important for global poverty alleviation: a spatial 
571Torres PC, Morsello C, Parry L, Barlow J, Ferreira J, Gardner T, Pardini R. 2018.

572 Landscape correlates of bushmeat consumption and hunting in a post-frontier

573 Amazonian region. Environmental Conservation 45: 315-323.

574Van Kerm P. 2007. Extreme incomes and the estimation of poverty and inequality

575 indicators from EU-SILC. IRISS Working Paper Series. Centre d'Etudes de

576 Populations, de Pauvreté et de Politiques Socio-Economiques, Luxembourg.

577Van Vliet N, Quiceno MP, Cruz D, Neves de Aquino LJ, Yagüe B, Schor T, Hernandez 578 S, Nasi R. 2015. Bushmeat networks link the forest to urban areas in the trifrontier

579 region between Brazil, Colombia, and Peru. Ecology and Society 20: 21

580 DOI:10.5751/ES-07782-200321.

581Valsecchi J, El-Bizri HR, Figueira JEC. 2014. Subsistence hunting of Cuniculus paca

582 in the middle of the Solimões River, Amazonas, Brazil. Brazilian Journal of Biology

583 74: 560-568.

584Vasco C, Sirén A. 2016. Correlates of wildlife hunting in indigenous communities in 585 the Pastaza province, Ecuatorian Amazonia. Animal Conservation 19: 422-429.

586Wilkie DS, Godoy RA. 2001. Income and price elasticities of bushmeat demand in 587 lowland Amerindian societies. Conservation Biology 15: 761-769.

588Wilkie DS, Starkey M, Abernethy K, Effa EN, Telfer P, Godoy R. 2005. Role of prices 589 and wealth in consumer demand for bushmeat in Gabon, Central Africa.

590 Conservation Biology 19: 268-274.

591WinklerPrins AMGA, Souza PS. 2005. Surviving the City: Urban Home Gardens and 592 the Economy of Affection in the Brazilian Amazon. Journal of Latin American 593 Geography 4: 107-126.

594Zuur AF, Ieno EN, Wlaker NJ, Saveliev AA, Smith GM. 2009. Mixed Effects Models 595 and Extensions in Ecology with R. $1^{\text {st }}$ edition. Springer, New York. 
596Table 1. GLMM model selection results for hunting $(n=240)$ showing only models with $\Delta$ AICc $\leq 3$ and the intercept-only model for reference.

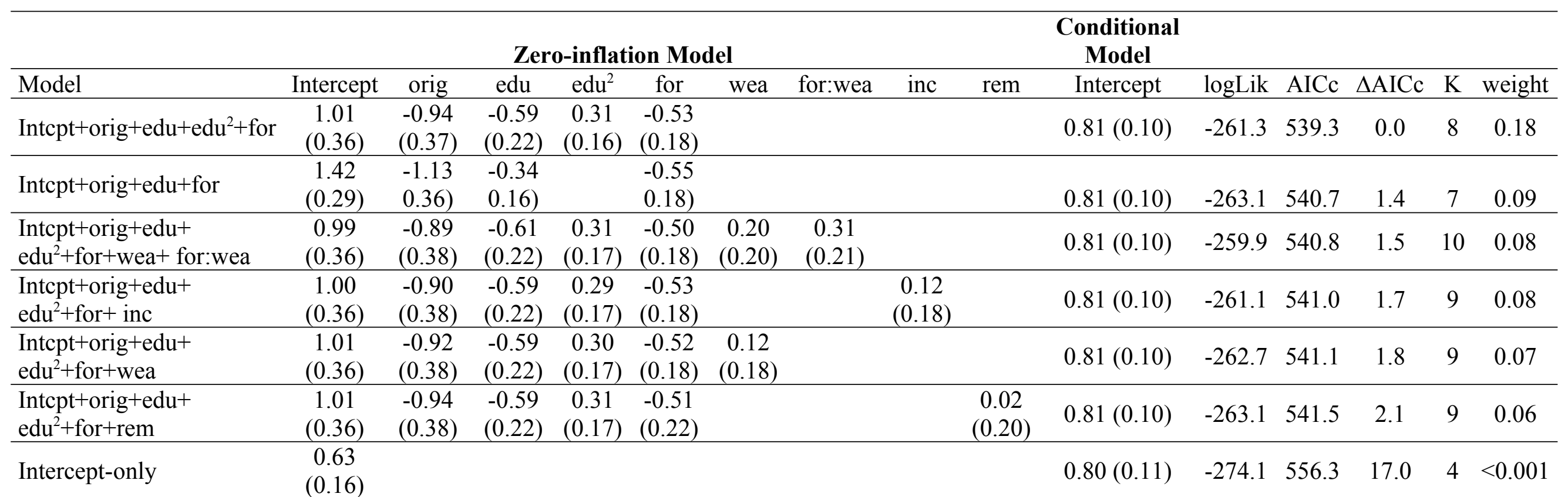

597Intcpt=Intercept, orig=Amazonian origin, edu=years of formal education of the male household head, for=forest cover, rem=remoteness,

598inc=monetary income, wea=asset-wealth; K: number of parameters; logLik: log-Likelihood of the model; AICc: AICc value; $\Delta$ AICc: difference

599in AICc value compared to the first-ranked model; $\omega$ i: Akaike weight; coefficients for each variable of the model. In parenthesis = SE. Zero-

600 inflation Model - estimates the probability of not have hunted (binary variable). Conditional Model - frequency variable. 


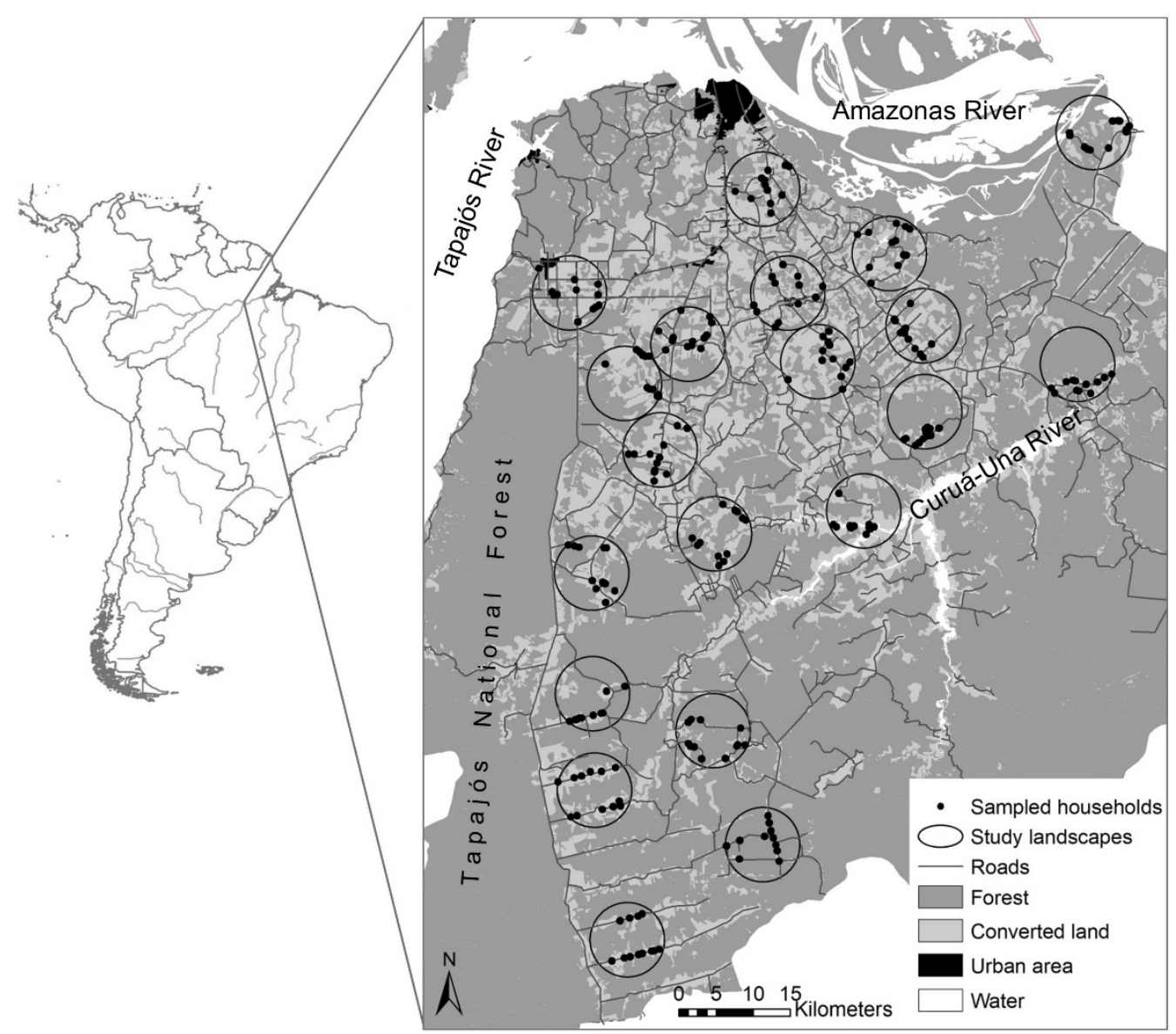

601

602Figure 1. Location of the study region in South America and land-cover map of the 603 study region, indicating the location of the 20 study landscapes and the 240 sampled 604households.

605

606

607

608

609 
(a)

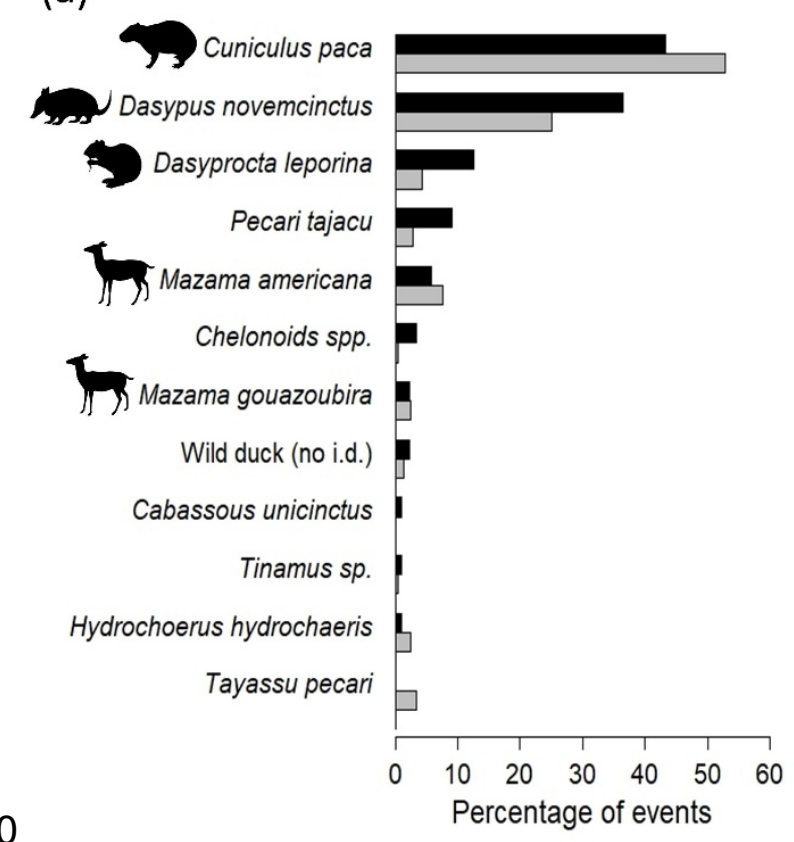

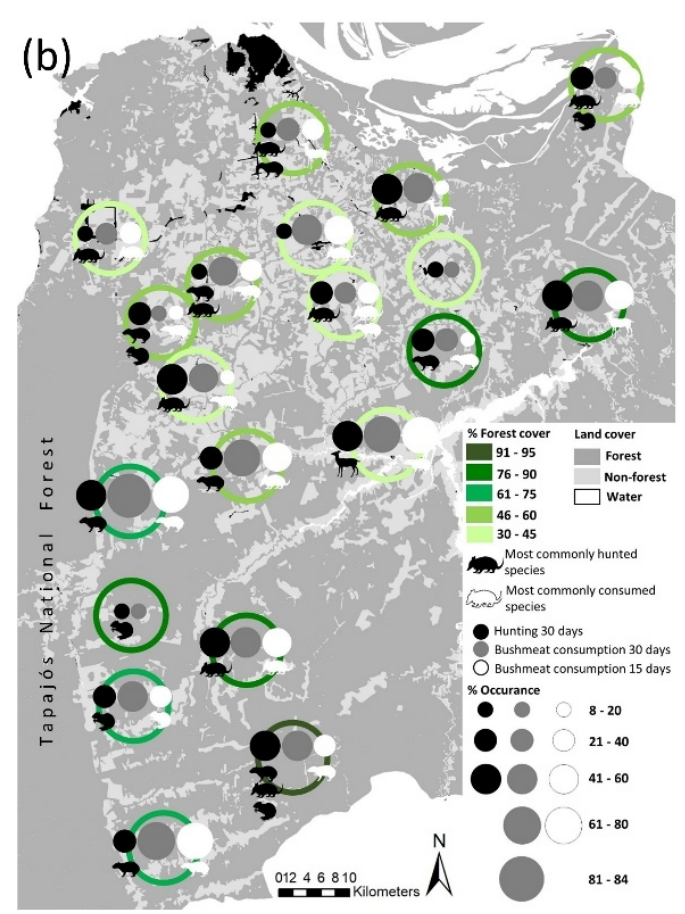

611Figure 2. Species hunted and consumed in the study region. (a) Percentage of hunting 612 $(n=88)$ and meal $(n=208)$ events where the species was hunted (black) or consumed 613(grey). Totals sum to more than $100 \%$ because more than one species could have been 614 hunted or consumed in the same event. (b) Percentage of households that hunted and 615 consumed bushmeat and species most commonly hunted and consumed in each 616 landscape. More than one species could me hunted or consumed in the same number of 617 events or no species could have been hunted or consumed in a given landscape.

\section{8}



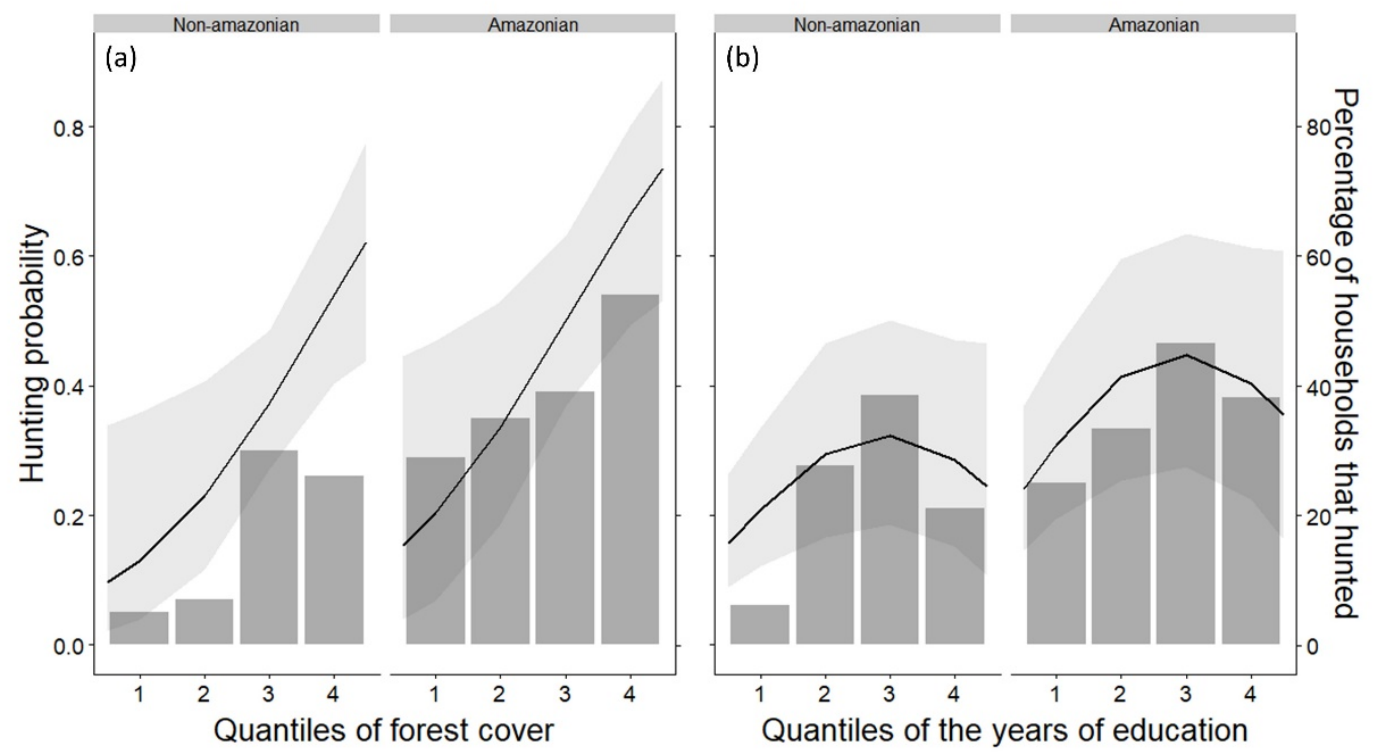

624

625Figure 3. Relationships between hunting activity and (a) origin and forest cover; (b) 626 origin and reliance on non-monetary income. Bars represent raw data. Curves represent 627 hunting probability predicted by the first model selected $(95 \% \mathrm{CI})$.

628

629

630

631

632

633

634

635

636

637

638

639

640

641 